\title{
Substituição parcial de farelo de soja por ureia de liberação lenta em rebanhos leiteiros comerciais
}

\author{
Partial replacement of soybean meal by slow release urea in commercial dairy herds
}

SILVEIRA, Vítor Augusto ${ }^{1}$; LOPES, Naína Magalhães ${ }^{1}$; OLIVEIRA, Rafael Caputo ${ }^{1}$; GONZALES, Bruno ${ }^{1}$; SIQUEIRA, Alexandre Valise ${ }^{1}$; BIER, Luiz Pedro Poletti ${ }^{2}$; ZONI, Mario Sérgio ${ }^{3}$; GIARDINI, Winston ${ }^{4}$; PEREIRA, Renata Apocalypse Nogueira ${ }^{5}$; ALMEIDA, Rodrigo de ${ }^{2}$; PEREIRA, Marcos Neves ${ }^{1^{*}}$

\author{
${ }^{1}$ Universidade Federal de Lavras, Lavras, Minas Gerais, Brasil. \\ ${ }^{2}$ Universidade Federal do Paraná, Curitiba, Paraná, Brasil. \\ ${ }^{3}$ Milkonsult, Castro, Paraná, Brasil. \\ ${ }^{4}$ Alltech do Brasil, Curitiba, Paraná, Brasil. \\ ${ }^{5}$ Empresa de Pesquisa Agropecuária de Minas Gerais, Lavras, Minas Gerais, Brasil. \\ *Endereço para correspondência: mpereira@dzo.ufla.br
}

\section{RESUMO}

Dois experimentos foram conduzidos para avaliar a substituição parcial de farelo de soja por ureia encapsulada (Optigen ${ }^{\circledR} \mathrm{II}$, Alltech do Brasil, Curitiba, PR, Brasil). Na dieta Controle, $1 \mathrm{~kg}$ de farelo de soja foi substituído por mistura isonitrogenada que continha $160 \mathrm{~g}$ de Optigen ${ }^{\circledR} \mathrm{II}$ $+2,5 \mathrm{~kg}$ de silagem de milho no Exp.1, ou $150 \mathrm{~g}$ de Optigen ${ }^{\circledR}$ II $+850 \mathrm{~g}$ de milho moído fino no Exp.2. No Exp.1, 61 vacas Holandês foram blocadas e alocadas a um tratamento por 21 dias, e as medidas da mesma variável no final da padronização utilizadas como covariável. No Exp.2, 97 vacas foram alocadas a uma sequência dos dois tratamentos por 21 dias, em delineamento de reversão simples. A resposta aos tratamentos foi avaliada do dia 17 ao 21 . Em ambos os experimentos, não houve diferenças entre os tratamentos na composição em nutrientes da dieta oferecida e das sobras, nas sobras como \% do oferecido, no peso vivo e no escore de condição corporal dos animais. A produção diária de leite foi $38,4 \mathrm{~kg} / \mathrm{d}$ no Controle e 38,9 no Optigen ${ }^{\circledR} \mathrm{II} \quad(\mathrm{P}=0,62)$ no Exp.1, e $27,0 \mathrm{~kg} / \mathrm{d}$ e 27,2 no Exp.2 $(\mathrm{P}=0,64)$, respectivamente. A ureia encapsulada reduziu a porcentagem de gordura no leite no Exp.2 $(\mathrm{P}=0,04)$. O Optigen ${ }^{\circledR} \mathrm{II}$ aumentou o nitrogênio ureico no leite de 16,3 para $17,3 \mathrm{mg} / \mathrm{dL}$ no Exp.1 $(\mathrm{P}<0,01)$ e as relações entre o leite produzido e o alimento consumido $(\mathrm{P}=0,08)$ e entre a alantoína e a creatinina urinárias $(\mathrm{P}=0,03)$ no Exp.2. A substituição parcial de farelo de soja por Optigen ${ }^{\circledR}$ II não induziu queda no desempenho.

Palavras-chave: nitrogênio não proteico, Optigen, ureia encapsulada

\section{SUMMARY}

Two experiments evaluated the partial replacement of soybean meal by encapsulated urea (Optigen ${ }^{\circledR}$ II, Alltech do Brasil, Curitiba, PR, Brasil). From a Control diet, $1 \mathrm{~kg}$ of soybean meal was replaced by an isonitrogenous mixture containing $160 \mathrm{~g}$ of Optigen ${ }^{\circledR} \mathrm{II}+2.5 \mathrm{~kg}$ of corn silage in Exp.1, or $150 \mathrm{~g}$ of Optigen ${ }^{\circledR} \mathrm{II}+850 \mathrm{~g}$ of finely ground corn in Exp.2. In Exp.1, 61 Holstein cows were blocked and allocated to a treatment for 21 days, and measures of the same variable at the end of the standardization period were used as covariate. In Exp.2, 97 cows were allocated to a sequence of two treatments for 21 days, in a simple reversal (crossover) design. Response to treatments was evaluated from day 17 to 21 . In both experiments, the nutrient composition of the offered diet and orts, orts as a $\%$ of the offered, body weight, and body condition score of the animals did not differ across treatments. Daily milk yield was $38.4 \mathrm{~kg} / \mathrm{d}$ for Control and 38.9 for Optigen ${ }^{\circledR} \mathrm{II}$ in 
Exp.1 $(P=0.62)$, and $27.0 \mathrm{~kg} / \mathrm{d}$ and 27.2 in Exp.2 $(\mathrm{P}=0.64)$, respectively. Encapsulated urea decreased milk fat content in Exp.2 $(\mathrm{P}=0.04)$. Optigen ${ }^{\circledR} \mathrm{II}$ increased milk urea nitrogen from 16.3 to $17.3 \mathrm{mg} / \mathrm{dL}$ in Exp. $1(\mathrm{P}<0.01)$ and the ratios of milk produced to feed consumed $(\mathrm{P}=0.08)$ and allantoin to creatinine in urine $(\mathrm{P}=0.03)$ in Exp.2. Replacing soybean meal with Optigen ${ }^{\circledR}$ II did not induce lower performance.

Keywords: encapsulated urea, non-protein nitrogen, Optigen

\section{INTRODUÇÃO}

A substituição de fontes de proteína verdadeira, como farelo de soja, por alimentos com alto teor de nitrogênio não proteico (NNP), como a ureia, pode reduzir o custo alimentar e possibilitar a formulação de dietas com maior inclusão de alimentos energéticos, subprodutos fibrosos ou forragens, e assim explorar a reconhecida capacidade dos ruminantes de sintetizar proteína microbiana de alto valor biológico a partir de NNP (NRC, 2001). Entretanto, a rápida hidrólise da ureia por ureases microbianas pode resultar em disponibilidade ruminal de $\mathrm{N}$ amoniacal em taxa superior à capacidade de síntese de proteína microbiana, o que implica na perda excessiva de $\mathrm{N}$ do rúmen para o sangue (LAPIERRE \& LOBLEY, 2001). Apenas $26 \%$ do $\mathrm{N}$ ingerido foi secretado como $\mathrm{N}$ no leite (SANTOS et al., 2011), e perdas de $\mathrm{N}$ na urina e fezes, superiores a 70\% do ingerido, são comuns em vacas leiteiras (JONKER et al., 2002; ARRIAGA et al., 2009). Este fato é preocupante devido aos possíveis impactos negativos do $\mathrm{N}$ excretado sobre o ambiente, como a potencial contaminação dos lençóis freáticos (ARRIAGA et al., 2009) e, ainda, do alto teor de nitrogênio ureico no sangue e no leite sobre a eficiência reprodutiva de vacas leiteiras (BUTLER, 1998; RAJALA-SCHULTZ et al., 2001).

Optigen ${ }^{\circledR}$ II, ureia encapsulada com reduzida velocidade de liberação do $\mathrm{N}$ no rúmen, tendeu a aumentar a síntese microbiana in vitro ao substituir a ureia (HARRISON et al., 2006). A tendência de aumento na relação entre a produção diária de leite e o consumo de matéria seca foi observada com substituição parcial de farelo de soja por mistura isonitrogenada de Optigen ${ }^{\circledR}$ II e polpa cítrica (SANTOS et al., 2011).

Souza et al. (2010) observaram que a substituição de farelo de soja por mistura isonitrogenada de Optigen ${ }^{\circledR} \mathrm{II}$ e casca de soja não deprimiu o desempenho de vacas com produção diária de $38 \mathrm{~kg}$. Inostroza et al. (2010) avaliaram a substituição parcial de farelo de soja por Optigen ${ }^{\circledR} \mathrm{II}$ em 16 rebanhos comerciais e observaram aumentos na produção diária de leite de 35,4 para $35,9 \mathrm{~kg}$ e no conteúdo de nitrogênio ureico no leite (NUL) de 12,4 para $13,2 \mathrm{mg} / \mathrm{dL}$.

O objetivo deste trabalho foi avaliar a resposta de vacas leiteiras à substituição parcial de farelo de soja por Optigen ${ }^{\circledR}$ II. Nesse sentido, duas estratégias alimentares foram avaliadas: no Experimento 1, o farelo de soja foi substituído por mistura isonitrogenada de Optigen ${ }^{\circledR} \mathrm{II}$ e silagem de milho, já no Experimento 2, a substituição foi por Optigen ${ }^{\circledR}$ II e milho maduro finamente moído.

\section{MATERIAIS E MÉTODOS}

Os experimentos foram conduzidos em dois rebanhos leiteiros comerciais do estado do Paraná. Uma equipe de três pesquisadores esteve presente, continuamente, em cada rebanho, e foi 
responsável pela administração dos tratamentos e coleta de dados.

No Experimento 1, 68 vacas da raça Holandês foram alojadas em um curral tipo free stall, por cinco dias préexperimentais e ao longo dos 21 dias de aplicação dos tratamentos. Nesse curral não houve a entrada de novas vacas durante o experimento.

Durante os cinco dias pré-experimentais foi mensurada a produção de leite de cada animal e amostras compostas das três ordenhas diárias foram formadas diariamente para mensuração dos teores de gordura, proteína, lactose, sólidos totais, contagem de células somáticas (CCS) e nitrogênio ureico no leite (NUL). As amostras foram coletadas em frascos que continham conservante 2-bromo-2nitropropano-1-3-diol, e foram analisadas no Laboratório Centralizado da Associação Paranaense de Criadores de Bovinos da Raça Holandesa (APCBRH, Curitiba, PR).

A CCS foi transformada em uma escala linear de 0 a 9 (CCS linear), sendo o ponto médio de cada escore linear representado pelos seguintes valores de CCS (x 1000 células/mL): 12,5 para CCS linear 0; 25 para CCS linear 1; 50 para CCS linear 2; 100 para CCS linear 3; 200 para CCS linear 4; 400 para CCS linear 5; 800 para CCS linear 6; 1600 para CCS linear 7; 3200 para CCS linear 8 e 6400 para CCS linear 9. No final desse período, o peso vivo foi estimado por fita de perímetro torácico e a condição corporal foi avaliada em escala de 1 a 5 pontos (Wildman et al., 1982) por dois avaliadores independentes. Esses dados, coletados no período pré-experimental, foram incluídos como covariável no modelo de análise estatística.

Ao final do período pré-experimental, as vacas foram blocadas em pares, primariamente, por ordem de parto (primíparas ou vacas com dois ou mais partos) e, secundariamente, por produção média de leite nos cinco dias pré-experimentais. Entre as 68 vacas inicialmente alocadas, 10 recebiam somatotropina bovina (bST) e por isso, formaram cinco blocos a parte, também pareados por ordem de parto $\mathrm{e}$ produção. Dentro de cada bloco, os animais foram aleatoriamente alocados a um dos dois tratamentos, Optigen ${ }^{\circledR} \mathrm{II}$ ou Controle, por 21 dias, e a resposta aos tratamentos avaliada entre os dias 17 e 21.

O peso vivo e a condição corporal de cada vaca foi mensurada no dia 21. Das 68 vacas que participaram do período pré-experimental, 61 terminaram 0 experimento; 31 vacas no tratamento Optigen ${ }^{\circledR}$ II e 30 no grupo Controle, já que perdas de sete unidades experimentais ocorreram por mastite e problemas de casco. O parâmetro dias em lactação no primeiro dia do período pré-experimental foi $245 \pm 88$ (média \pm desvio padrão) e as vacas tinham $3,0 \pm 1,4$ partos no Optigen ${ }^{\circledR} \mathrm{II}$, e $241 \pm 79$ e $2,6 \pm 1,3$ no Controle, respectivamente.

$\mathrm{O}$ curral foi dividido fisicamente em duas metades, cada uma recebeu os tratamentos Controle ou Optigen ${ }^{\circledR}$ II. Os dois grupos de animais foram alimentados, simultaneamente, três vezes por dia com a mesma dieta basal oferecida na forma de dieta total misturada (Tabela 1). Os tratamentos foram acrescidos e misturados manualmente à dieta basal. Para cada $100 \mathrm{~kg}$ de dieta basal foram acrescidos $5,45 \mathrm{~kg}$ de matéria natural de uma mistura que continha $95 \%$ de silagem de milho (27,6\% de matéria seca) e $5 \%$ de Optigen ${ }^{\circledR} \mathrm{II}$ ou $1,93 \mathrm{~kg}$ de farelo de soja no tratamento Controle. A quantidade oferecida diariamente de Optigen ${ }^{\circledR}$ II por vaca foi de 160 gramas e a de farelo de soja foi $1 \mathrm{~kg}$. Os teores nutricionais almejados da dieta total 
foram: 49,3\% de matéria seca (MS) na matéria natural, $17,5 \%$ de proteína bruta (PB) na MS e 32,1\% de fibra em detergente neutro (FDN) na MS.
Nos dias 17 a 21, a quantidade oferecida de dieta total (dieta basal acrescida dos tratamentos) em cada alimentação e a sobra diária de cocho foi mensurada.

Tabela 1. Composição da dieta basal em ingredientes (\% da MS). Experimento 1

\begin{tabular}{|c|c|}
\hline Ingredientes & $\%$ da $\mathrm{MS}$ \\
\hline Silagem de milho $(27,6 \% \mathrm{MS}, 7,6 \% \mathrm{~PB}, 54,9 \% \mathrm{FDN})$ & 36,1 \\
\hline Silagem pré-secada de azevém ( $45,6 \% \mathrm{MS}, 22,9 \% \mathrm{~PB}, 51,1 \% \mathrm{FDN})$ & 8,7 \\
\hline Concentrado comercial & 29,4 \\
\hline Caroço de algodão & 9,4 \\
\hline Milho maduro moído fino & 8,2 \\
\hline Farelo de soja & 6,0 \\
\hline Mistura mineral ${ }^{1}$ & 0,4 \\
\hline Bicarbonato de sódio & 0,6 \\
\hline Sabão de cálcio de ácidos graxos oriundos de soja (Megalac $\left.{ }^{\circledR}\right)$ & 0,8 \\
\hline Óxido de magnésio & 0,3 \\
\hline
\end{tabular}

Amostras da dieta total foram obtidas, diariamente e por tratamento, em cinco pontos ao longo do cocho, em cada uma das três alimentações diárias, formando uma amostra composta para congelamento. Amostras das sobras diárias, das forragens e dos compostos diários da dieta total oferecida entre os dias 17 e 21 foram analisadas para MS, $\mathrm{PB}$ e FDN. O teor de MS foi determinado por desidratação em estufa ventilada por 72 horas a $58^{\circ} \mathrm{C}$ e posterior moagem das amostras em peneira de $1 \mathrm{~mm}$, em moinho tipo Thomas Willey. Uma sub-amostra foi levada à estufa a $100^{\circ} \mathrm{C}$ por 24 horas para determinação do teor de MS. A PB foi determinada por aparelho de destilação a vapor Microkjeldhal. A FDN foi determinada por análise não sequencial, de acordo com Van Soest et al. (1991). A técnica de FDN utilizou 0,5g de sulfito de sódio e $200 \mu l$ de $\alpha$-amilase, $100 \mu \mathrm{l}$ adicionados ao becker durante a fervura da amostra em solução de detergente neutro e $100 \mu \mathrm{l}$ quando da filtragem, em cadinho, com água quente.

A sobra diária foi calculada como proporção da matéria natural oferecida. $\mathrm{O}$ consumo de matéria seca, de nutrientes do lote e o teor de nutrientes na dieta consumida foram calculados, considerando a composição do oferecido e das sobras diárias. A produção média de leite do lote, a cada dia de mensuração do consumo, foi utilizada para calcular a eficiência leiteira, ao dividir a produção pelo consumo de MS do grupo de animais.

Uma amostra de urina foi coletada de cada animal entre os dias 17 a 21 do período para estimativa da relação entre a concentração de alantoína e a de creatinina, utilizada como medida relativa da síntese de proteína microbiana. A amostra foi diluída na proporção $3: 2$, com solução a $4 \%$ de ácido sulfúrico e imediatamente congelada a $-20^{\circ} \mathrm{C}$, para posterior análise de alantoína (CHEN \& GOMES, 
1995) e creatinina (Labtest Diagnóstica S.A, Lagoa Santa, MG. Cat.35-100).

No Experimento 2, as 120 vacas da raça Holandês foram alojadas em free stall por 42 dias sem que fosse permitida a entrada de novos animais ao longo do período de coleta de dados. Uma vez que 23 vacas deixaram o lote experimental ao longo destes 42 dias, em decorrência de secagens, descartes por falha reprodutiva e problemas de casco ou por mastite, dados de somente 97 unidades experimentais foram utilizadas na análise final. Os animais estavam com $291 \pm 127$ dias em lactação, no primeiro dia experimental, com

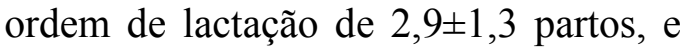
apenas quatro vacas eram primíparas.

As vacas foram blocadas em pares com base na produção diária de leite. Dentro de cada bloco, cada animal foi aleatoriamente alocado a uma sequência dos dois tratamentos em dois períodos de 21 dias, em delineamento de reversão simples. Mensurações foram realizadas na terceira semana (dias 17 a 21) de cada período experimental. O curral foi dividido fisicamente em duas metades, cada uma recebendo os tratamentos Controle ou Optigen ${ }^{\circledR} \mathrm{II}$, acrescidos à dieta basal do rebanho.

Os dois grupos de animais foram alimentados simultaneamente três vezes por dia com a mesma dieta basal, oferecida na forma de dieta total misturada (Tabela 2). Para cada $100 \mathrm{~kg}$ de matéria natural de dieta basal oferecida foram acrescidos $4,18 \mathrm{~kg}$ de matéria natural de pré-misturas, contendo os tratamentos (Tabela 3 ).

Foram oferecidas, diariamente, por vaca, as quantidades de 152 gramas de Optigen ${ }^{\circledR}$ II e $1 \mathrm{~kg}$ de farelo de soja. As pré-misturas foram acrescidas $\mathrm{e}$ misturadas manualmente à dieta basal. Os teores nutricionais almejados da dieta total foram: $47,8 \%$ de MS na $\mathrm{MN}$, $17,7 \%$ de $\mathrm{PB}$ na MS e $33,1 \%$ de FDN na MS.

Nos dias 17 a 21, a quantidade oferecida de dieta basal e das pré-misturas com os tratamentos, em cada alimentação, e a sobra diária de cocho foi mensurada. Amostras da dieta basal oferecida foram obtidas, por tratamento, em cinco pontos ao longo do cocho, em cada uma das três alimentações diárias, as quais formaram uma amostra composta para congelamento. Ao final de cada dia, uma amostra composta do oferecido foi formada. Amostras das forragens, das pré-misturas com os tratamentos, da sobra diária de cocho e dos compostos da dieta basal foram analisados para MS, PB e FDN, como descrito para o Experimento 1. A sobra diária de cocho, o consumo de matéria seca e de nutrientes do lote, o teor de nutrientes na dieta consumida, a eficiência leiteira do lote foram calculados como anteriormente descrito.

Tabela 2. Composição da dieta basal em ingredientes (\% da MS). Experimento 2

\begin{tabular}{lc}
\hline Ingredientes & \% da MS \\
\hline Silagem de milho (24,5\% MS, 9,6\% PB, 53,9\% FDN) & 30,8 \\
Silagem pré-secada de azevém (37,5\% MS, 13,3\% PB, 65,4\% FDN) & 13,5 \\
Silagem de soja (28,1\% MS, 15,2\% PB, 61,3\% FDN) & 5,1 \\
Concentrado comercial & 27,6 \\
Caroço de algodão & 11,5 \\
Milho maduro moído fino & 7,5 \\
Farelo de soja & 3,7 \\
Sabão de cálcio de ácidos graxos oriundos de soja (Megalac®) & 0,5 \\
\hline
\end{tabular}


Rev. Bras. Saúde Prod. Anim., Salvador, v.13, n.2, p.383-395 abr./jun., 2012 http://www.rbspa.ufba.br ISSN 15199940

Tabela 3. Composição das pré-misturas nos tratamentos Optigen ${ }^{\circledR}$ II e Controle. Experimento 2

\begin{tabular}{|c|c|c|}
\hline \multirow{2}{*}{ Item } & Optigen ${ }^{\circledR}$ II & Controle \\
\hline & \multicolumn{2}{|c|}{$\%$ da matéria natural } \\
\hline Bicarbonato de sódio & 7,5 & 7,5 \\
\hline Farelo de soja & - & 50,0 \\
\hline Fosfato bicálcico & 4,0 & 4,0 \\
\hline Milho maduro moído fino & 62,5 & 20,0 \\
\hline Levedura (Milk-Sacc X®) & 2,0 & 2,0 \\
\hline Optigen ${ }^{\circledR}$ II & 7,5 & - \\
\hline Óxido de magnésio & 3,0 & 3,0 \\
\hline Cloreto de sódio & 3,5 & 3,5 \\
\hline Mistura mineral $^{1}$ & 10,0 & 10,0 \\
\hline Matéria seca & 91,0 & 92,0 \\
\hline Proteína bruta & 24,9 & 24,1 \\
\hline Fibra em detergente neutro & 10,0 & 14,9 \\
\hline
\end{tabular}

As vacas foram ordenhadas três vezes ao dia. A produção de cada vaca foi mensurada e amostras foram coletadas entre os dias 17 a 21 de cada período. Amostras de leite foram obtidas e analisadas similarmente ao descrito no Experimento 1. O peso vivo foi estimado por determinação do perímetro torácico, e a condição corporal de cada vaca foi mensurada por três avaliadores, independentes, no dia 16 de cada período, para descrever as unidades experimentais. Uma amostra de urina foi coletada de cada animal, entre os dias 17 a 21 de cada período para estimativa da excreção de alantoína e creatinina, utilizada como medida relativa da síntese diária de proteína microbiana. $\mathrm{O}$ procedimento para amostragem e análises foi semelhante ao descrito no Experimento 1. Os dados do Experimento 1 foram analisados pelo procedimento GLM do SAS (2004), com modelo contendo os efeitos de covariável (medida da mesma variável no período pré-experimental), bloco (1 a 34) e tratamento (Optigen ${ }^{\circledR} \mathrm{II}$ ou Controle). Os dados de consumo e conversão alimentar foram analisados mediante uso de dia de coleta (17 a 21 ), em modelo contendo apenas o efeito de tratamento.

Os dados do Experimento 2 foram analisados pelo procedimento GLM do SAS (2004) por modelo contendo os efeitos de vaca (1 a 97), período (1 ou 2) e tratamento (Optigen ${ }^{\circledR}$ II ou Controle). Os dados de consumo e conversão alimentar utilizaram dia de coleta como unidade experimental e modelo contendo os efeitos de período, tratamento e a interação entre período e tratamento. Não houve interação significativa entre período e tratamento para qualquer das variáveis (P variando de 0,17 a 0,82 ).

\section{RESULTADOS E DISCUSSÃO}

No Experimento 1, o percentual de sobra ao redor de $5 \%$ do oferecido não diferiu entre tratamentos (Tabela 4). A tendência $(\mathrm{P}=0,10)$ de menor teor de MS no oferecido e nas sobras no 
tratamento Optigen ${ }^{\circledR}$ II é coerente, uma vez que a silagem de milho com teor de MS ao redor de $28 \%$ substituiu o farelo de soja nesse tratamento. Houve similaridade entre tratamentos nas concentrações de PB e FDN da dieta oferecida e da sobra.

Resultado semelhante foi observado no Experimento 2, mesmo com proporção de sobra, relativamente ao oferecido, de apenas 2,5\% (Tabela 5). A similaridade entre os tratamentos na proporção de sobra e na composição da dieta e sobra sugere que foi atendida a meta de obter dietas isonutricionais, necessária para que fosse avaliada a substituição de farelo de soja pela mistura de Optigen ${ }^{\circledR}$ II e silagem de milho, no Experimento 1, e Optigen ${ }^{\circledR}$ II e milho finamente moído, no Experimento 2. As metodologias de incorporação dos tratamentos à dieta basal foram eficientes.

Tabela 4. Composição da dieta oferecida e da sobra alimentar. Experimento 1

\begin{tabular}{|c|c|c|c|c|}
\hline \multirow{2}{*}{$\begin{array}{l}\text { Item } \\
\text { Sobra de matéria natural }\end{array}$} & \multicolumn{2}{|c|}{$\begin{array}{c}\text { Controle Optigen }{ }^{\circledR} \mathrm{II} \\
\% \text { do oferecido }\end{array}$} & \multirow{2}{*}{$\begin{array}{c}\text { EPM }^{1} \\
0,54\end{array}$} & \multirow{2}{*}{$\begin{array}{c}P \text { Trat }^{2} \\
0,46\end{array}$} \\
\hline & 4,7 & 5,3 & & \\
\hline \multicolumn{5}{|c|}{$\%$ da matéria natural } \\
\hline Matéria seca da dieta & 46,4 & 45,0 & 0,51 & 0,10 \\
\hline Matéria seca da sobra & 44,4 & 41,0 & 1,34 & 0,11 \\
\hline \multicolumn{5}{|c|}{$\%$ da matéria seca } \\
\hline Proteína bruta da dieta & 17,9 & 17,5 & 0,46 & 0,48 \\
\hline Proteína bruta da sobra & 16,4 & 16,4 & 0,19 & 0,99 \\
\hline Fibra em detergente neutro da dieta & 38,8 & 38,5 & 1,38 & 0,89 \\
\hline Fibra em detergente neutro da sobra & 39,2 & 38,5 & 0,79 & 0,56 \\
\hline
\end{tabular}

${ }^{1} \mathrm{EPM}=$ Erro padrão das médias.

${ }^{2} \mathrm{P}$ Trat $=$ Probabilidade do teste $\mathrm{F}$ para efeito de tratamento.

O teor de PB foi menor na sobra que na dieta oferecida, enquanto o teor de FDN aumentou na sobra (Tabelas 4 e 5), mostrando que os animais selecionaram a favor de alimentos com maior densidade proteica e energética. Entretanto, proporcionalmente ao teor nutricional do oferecido, a variação no teor nutricional da sobra foi menor no Experimento 1.

A sobra abaixo de 3\% parece ter induzido seletividade mais acentuada que sobra ao redor de $5 \%$, obviamente com a ressalva que as dietas eram distintas em teor de ingredientes.
Nos dois rebanhos, o teor de $\mathrm{PB}$ na dieta total oferecida (Tabelas 4 e 5) foi semelhante ao teor almejado pela formulação, 17,5\% no Experimento 1, e $17,7 \%$ no Experimento 2. Entretanto, em ambos os rebanhos o teor de FDN do oferecido foi acima do almejado, $32,1 \%$ no Experimento 1, e $33,1 \%$ no Experimento 2. Esse fato sugere que o teor de FDN das forragens pode ter sido subestimado durante a formulação das dietas experimentais, enquanto o teor de energia foi superestimado. 
Rev. Bras. Saúde Prod. Anim., Salvador, v.13, n.2, p.383-395 abr./jun., 2012 http://www.rbspa.ufba.br ISSN 15199940

Tabela 5. Composição da dieta oferecida e da sobra alimentar. Experimento 2

\begin{tabular}{|c|c|c|c|c|}
\hline Item & \multicolumn{2}{|c|}{$\begin{array}{c}\text { Controle Optigen }{ }^{\circledR} \mathrm{II} \\
\% \text { do oferecido }\end{array}$} & \multirow{2}{*}{$\begin{array}{c}\text { EPM }^{1} \\
0,88\end{array}$} & \multirow{2}{*}{$\begin{array}{c}P \text { Trat }^{2} \\
0,74\end{array}$} \\
\hline \multirow[t]{2}{*}{ Sobra de matéria natural } & 2,7 & 2,3 & & \\
\hline & \multicolumn{2}{|c|}{$\%$ da matéria natural } & & \\
\hline Matéria seca da dieta basal & 41,4 & 40,4 & 0,72 & 0,33 \\
\hline Matéria seca da dieta total & 43,5 & 42,4 & 0,69 & 0,30 \\
\hline \multirow[t]{2}{*}{ Matéria seca da sobra } & 41,5 & 41,6 & 1,84 & 0,96 \\
\hline & \multicolumn{2}{|c|}{$\%$ da matéria seca } & & \\
\hline Proteína bruta da dieta basal & 16,6 & 16,3 & 0,28 & 0,44 \\
\hline Proteína bruta da dieta total & 17,3 & 17,1 & 0,26 & 0,60 \\
\hline Proteína bruta da sobra & 15,3 & 15,8 & 0,53 & 0,52 \\
\hline Fibra em detergente neutro da dieta basal & 42,5 & 41,7 & 0,63 & 0,39 \\
\hline Fibra em detergente neutro da dieta total & 39,6 & 38,6 & 0,56 & 0,24 \\
\hline Fibra em detergente neutro da sobra & 45,6 & 45,7 & 1,11 & 0,93 \\
\hline
\end{tabular}

${ }^{\mathrm{T}} \mathrm{EPM}=$ Erro padrão das médias.

${ }^{2} P$ Trat $=$ Probabilidade do teste $\mathrm{F}$ para efeito de tratamento.

Monitoramento para ajuste dietético do teor de fibra dos alimentos parece ser mais pertinente que ajuste no nitrogênio dietético nesses rebanhos. Uma explicação plausível para a menor precisão no balanceamento de carboidratos é a variabilidade no teor de fibra entre partidas de silagem ou entre silos. Manter a oferta constante de uma mesma forragem ao longo do período de coleta de dados seria uma recomendação para aumentar a precisão em experimentos de nutrição conduzidos em fazendas, apesar da implementação desta prática ser difícil, principalmente em rebanhos com elevado número de animais relativamente ao tamanho dos silos.

Não foi detectado efeito de tratamento $(\mathrm{P}>0,62)$ sobre a produção diária de leite (Tabelas 6 e 7). Quando o espaço da formulação gerado pela remoção parcial do farelo de soja da dieta foi ocupado por silagem de milho, vacas alimentadas com Optigen ${ }^{\circledR} \mathrm{II}$ mantiveram altas produções de leite, acima de $38 \mathrm{~kg}$ diários (Tabela 6), mesmo consumindo uma dieta com maior teor de forragem. A secreção diária de sólidos também não variou ( $\mathrm{P}>0,44)$ com os tratamentos, em conformidade ao previamente relatado por Galo et al. (2003) e Santos et al. (2011). Entretanto, no Experimento 2, foi observada queda $(\mathrm{P}=0,04)$ de 0,07 pontos percentuais no teor de gordura do leite no tratamento Optigen ${ }^{\circledR} \mathrm{II}$, semelhante ao observado por Souza et al. (2010). A queda no teor de gordura é coerente ao pequeno aumento no teor dietético de amido de milho no tratamento Optigen ${ }^{\circledR}$ II.

A substituição de farelo de soja por Optigen ${ }^{\circledR}$ II mais silagem de milho, no Experimento 1, aumentou $(\mathrm{P}<0,01)$ o teor de NUL (Tabela 6), efeito não detectado quando o uso de Optigen ${ }^{\circledR} \mathrm{II}$ foi acompanhado de aumento simultâneo no teor dietético de amido oriundo de milho maduro, finamente moído, no Experimento 2 (Tabela 7). 
Tabela 6. Produção, composição do leite e descrição dos animais. Experimento 1

\begin{tabular}{|c|c|c|c|c|}
\hline \multirow{2}{*}{ Item } & Controle & Optigen ${ }^{\circledR} \mathrm{II}$ & \multirow{2}{*}{$\mathrm{EPM}^{1}$} & \multirow{2}{*}{$P$ Trat $^{2}$} \\
\hline & \multicolumn{2}{|c|}{$\mathrm{kg} / \mathrm{d}$} & & \\
\hline Leite & 38,4 & 38,9 & 0,60 & 0,62 \\
\hline Gordura & 1,328 & 1,320 & 0,0199 & 0,76 \\
\hline Proteína & 1,268 & 1,275 & 0,0192 & 0,80 \\
\hline Lactose & 1,763 & 1,769 & 0,0320 & 0,90 \\
\hline \multirow[t]{2}{*}{ Sólidos totais } & 4,745 & 4,763 & 0,0767 & 0,87 \\
\hline & \multicolumn{2}{|c|}{$\%$} & & \\
\hline Gordura & 3,46 & 3,40 & 0,035 & 0,30 \\
\hline Proteína & 3,31 & 3,29 & 0,016 & 0,54 \\
\hline Lactose & 4,58 & 4,57 & 0,018 & 0,74 \\
\hline \multirow[t]{2}{*}{ Sólidos totais } & 12,30 & 12,31 & 0,056 & 0,80 \\
\hline & \multicolumn{2}{|c|}{ x 1000 células/mL } & & \\
\hline \multirow{2}{*}{ Contagem de células somáticas } & 320 & 252 & \multirow[t]{2}{*}{69,9} & \multirow[t]{2}{*}{0,51} \\
\hline & & & & \\
\hline \multirow{2}{*}{ Contagem de células somáticas linear } & 3,61 & 3,86 & \multirow[t]{2}{*}{0,17} & \multirow[t]{2}{*}{0,33} \\
\hline & & & & \\
\hline \multirow{2}{*}{ Nitrogênio ureico do leite } & 16,3 & 17,3 & \multirow[t]{2}{*}{0,20} & \multirow[t]{2}{*}{$<0,01$} \\
\hline & & & & \\
\hline \multirow{2}{*}{ Relação alantoína/creatinina } & 0,99 & 1,11 & \multirow[t]{2}{*}{0,075} & \multirow[t]{2}{*}{0,31} \\
\hline & & & & \\
\hline \multirow{2}{*}{ Perímetro torácico } & 213,7 & 213,5 & \multirow[t]{2}{*}{0,93} & \multirow[t]{2}{*}{0,91} \\
\hline & & & & \\
\hline \multirow{2}{*}{ Peso vivo } & 698 & 696 & \multirow[t]{2}{*}{5,9} & \multirow[t]{2}{*}{0,81} \\
\hline & & & & \\
\hline Condição corporal & 2,75 & 2,83 & 0,027 & 0,04 \\
\hline
\end{tabular}

${ }^{1} \mathrm{EPM}=$ Erro padrão das médias.

${ }^{2} P$ Trat $=$ Probabilidade do teste $\mathrm{F}$ para efeito de tratamento 
Rev. Bras. Saúde Prod. Anim., Salvador, v.13, n.2, p.383-395 abr./jun., 2012 http://www.rbspa.ufba.br ISSN 15199940

Tabela 7. Produção, composição do leite e descrição dos animais. Experimento 2

\begin{tabular}{|c|c|c|c|c|}
\hline Item & \multicolumn{2}{|c|}{$\mathrm{kg} / \mathrm{d}$} & $\mathrm{EPM}^{1}$ & $P$ Trat $^{2}$ \\
\hline Leite & 27,0 & 27,2 & 0,24 & 0,64 \\
\hline Gordura & 1,033 & 1,020 & 0,0131 & 0,51 \\
\hline Proteína & 0,921 & 0,928 & 0,0078 & 0,52 \\
\hline Lactose & 1,167 & 1,179 & 0,0106 & 0,44 \\
\hline \multirow[t]{2}{*}{ Sólidos totais } & 3,366 & 3,378 & 0,0327 & 0,80 \\
\hline & \multicolumn{2}{|c|}{$\%$} & & \\
\hline Gordura & 3,82 & 3,75 & 0,022 & 0,04 \\
\hline Proteína & 3,42 & 3,42 & 0,008 & 0,89 \\
\hline Lactose & 4,31 & 4,33 & 0,007 & 0,05 \\
\hline \multirow[t]{2}{*}{ Sólidos totais } & 12,46 & 12,43 & 0,026 & 0,43 \\
\hline & \multicolumn{2}{|c|}{ x 1000 células $/ \mathrm{mL}$} & & \\
\hline \multirow{2}{*}{ Contagem de células somáticas } & 326 & 323 & \multirow[t]{2}{*}{12,6} & \multirow[t]{2}{*}{0,90} \\
\hline & & & & \\
\hline \multirow{2}{*}{ Contagem de células somáticas linear } & 4,51 & 4,54 & \multirow[t]{2}{*}{0,052} & \multirow[t]{2}{*}{0,69} \\
\hline & & & & \\
\hline \multirow{2}{*}{ Nitrogênio ureico do leite } & 16,1 & 16,3 & \multirow[t]{2}{*}{0,07} & \multirow[t]{2}{*}{0,14} \\
\hline & & & & \\
\hline \multirow{2}{*}{ Relação alantoína/creatinina na urina } & 0,64 & 0,78 & \multirow[t]{2}{*}{0,035} & \multirow[t]{2}{*}{0,03} \\
\hline & & & & \\
\hline \multirow{2}{*}{ Perímetro torácico } & 218,9 & 217,9 & \multirow[t]{2}{*}{0,42} & \multirow[t]{2}{*}{0,09} \\
\hline & & & & \\
\hline \multirow{2}{*}{ Peso vivo } & 733 & 724 & \multirow[t]{2}{*}{2,5} & \multirow[t]{2}{*}{$<0,01$} \\
\hline & & & & \\
\hline Condição corporal & 3,02 & 3,05 & 0,025 & 0,41 \\
\hline
\end{tabular}

Inostroza et al. (2010) também observaram que a substituição parcial de farelo de soja por Optigen ${ }^{\circledR}$ II mais silagem de milho aumentou o teor de NUL em fazendas do Wisconsin. Esse fato não foi observado por Santos et al. (2011), quando o farelo de soja foi substituído por Optigen ${ }^{\circledR}$ II mais polpa cítrica, nem por Souza et al. (2010), quando o farelo de soja foi substituído por Optigen ${ }^{\circledR}$ II mais casca de soja. Esses resultados sugerem que, mesmo com baixa substituição de $\mathrm{N}$ de soja por $\mathrm{N}$ de Optigen ${ }^{\circledR} \mathrm{II}$, a estratégia de substituição de farelo de soja por concentrados energéticos parece induzir uma resposta mais desejável em NUL, comparativamente à substituição por carboidratos lentamente degradáveis de forrageiras, os quais não permitem um sincronismo ruminal tão preciso com a amônia produzida (VAN SOEST et al., 1991).

O consumo diário do grupo de vacas não diferiu entre tratamentos (Tabelas 8 e 9). Os valores observados ficaram abaixo do predito para esse grupo de animais pela metodologia do NRC (2001). O consumo predito para a vaca, com valores médios de produção de leite, peso vivo e estágio de lactação, no 
Experimento 1, foi $26,3 \mathrm{~kg} / \mathrm{d}$, e para a do Experimento 2, foi $23,3 \mathrm{~kg} / \mathrm{d}, 2,3$ e $2,0 \mathrm{~kg}$ acima do mensurado para o grupo de animais, respectivamente. Os valores experimentais, apesar de menores que os preditos, são coerentes biologicamente. Entretanto, a metodologia de mensuração do consumo do grupo mediante o uso de cada um dos cinco dias como unidade experimental, não foi capaz de dar suporte estatístico à diferença de $0,9 \mathrm{~kg}$ no consumo diário no Experimento 2 (Tabela 9).

Apesar da ausência em efeito de tratamento sobre o consumo do lote, houve tendência $(P=0,08)$ de maior eficiência leiteira quando Optigen ${ }^{\circledR} \mathrm{II}$ mais milho substituiu farelo de soja, no Experimento 2 (Tabela 9). Esse dado é similar ao observado por Santos et al. (2011), quando farelo de soja foi substituído por Optigen ${ }^{\circledR} \mathrm{II}$ mais polpa cítrica. Esse resultado sugere que a estratégia de substituir farelo de soja por Optigen ${ }^{\circledR}$ II e concentrados é mais promissora como forma de atuar sobre a eficiência biológica de vacas leiteiras do que o aumento no teor dietético de forragem.

Tabela 8. Consumo e eficiência leiteira do grupo de vacas. Experimento 1

\begin{tabular}{lcccc}
\hline \multirow{2}{*}{ Item } & Controle & Optigen ${ }^{\circledR} \mathrm{II}$ & $\mathrm{EPM}^{1}$ & $P$ Trat $^{2}$ \\
\cline { 2 - 5 } & \multicolumn{3}{c}{$\mathrm{kg} / \mathrm{d}$} \\
\hline Consumo de matéria seca & 23,8 & 24,1 & 0,45 & 0,61 \\
Consumo de proteína bruta & 4,3 & 4,2 & 0,11 & 0,67 \\
Consumo de fibra em detergente neutro & 9,2 & 9,3 & 0,18 & 0,82 \\
\hline \multicolumn{5}{c}{$\%$ do peso vivo } \\
\hline Consumo de fibra em detergente neutro & 1,31 & 1,34 & 0,027 & 0,52 \\
Leite/Consumo de matéria seca & 1,61 & 1,62 & 0,036 & 0,76 \\
\hline
\end{tabular}

${ }^{\mathrm{I}} \mathrm{EPM}=$ Erro padrão das médias.

${ }^{2} P$ Trat $=$ Probabilidade do teste $\mathrm{F}$ para efeito de tratamento.

Tabela 9. Consumo e eficiência leiteira do grupo de vacas. Experimento 2

\begin{tabular}{lrrrc}
\hline \multirow{2}{*}{ Item } & Controle & Optigen ${ }^{\circledR} \mathrm{II}$ & $\mathrm{EPM}^{1}$ & Trat $^{2}$ \\
\cline { 2 - 5 } & \multicolumn{4}{c}{$\mathrm{kg} / \mathrm{d}$} \\
\hline Consumo de matéria seca & 21,7 & 20,8 & 0,47 & 0,19 \\
Consumo de proteína bruta & 3,7 & 3,6 & 0,09 & 0,15 \\
Consumo de fibra em detergente neutro & 8,6 & 8,1 & 0,25 & 0,13 \\
\hline \multicolumn{4}{c}{$\%$ do peso vivo } \\
\hline Consumo de fibra em detergente neutro & 1,17 & 1,12 & 0,034 & 0,26 \\
Leite/Consumo de matéria seca & 1,25 & 1,32 & 0,028 & 0,08 \\
\hline
\end{tabular}

${ }^{\mathrm{T}} \mathrm{EPM}=$ Erro padrão das médias.

${ }^{2} P$ Trat $=$ Probabilidade do teste $\mathrm{F}$ para efeito de tratamento.

Houve aumento na relação entre alantoína e creatina na urina quando Optigen ${ }^{\circledR} \mathrm{II}$ acrescido de milho substituiu o farelo de soja no Experimento 2 (Tabela 7), provavelmente, como resultado do aumento na disponibilidade ruminal de 
amido dietético e seu possível efeito sobre a síntese de proteína microbiana no rúmen. Já no Experimento 1, embora sem diferença significativa $(\mathrm{P}=0,31)$ entre os tratamentos, houve aumento numérico nessa relação na urina, quando da substituição da soja por ureia encapsulada e silagem de milho (Tabela 6). A pequena inclusão de NNP em forma encapsulada pode ter determinado um melhor sincronismo entre a degradação ruminal de $\mathrm{N}$ e a degradação do amido, o que sugere benefícios à fermentação, mesmo quando o teor de $\mathrm{N}$ dietético não era limitante, a se julgar pelos satisfatórios níveis dietéticos de proteína bruta em ambos os ensaios (acima de 17\%PB) e pelo teor de NUL nos experimentos acima de $16 \mathrm{mg} / \mathrm{dL}$ (Tabelas 8 e 9).

Esse achado é interessante quando se considera a reciclagem de $\mathrm{N}$ para $\mathrm{o}$ rúmen (REYNOLDS \& KRISTENSEN, 2008). O aporte ruminal de $\mathrm{N}$ parece ter sido beneficiado pelo suprimento mais contínuo, oriundo da ureia encapsulada. A substituição de farelo de soja por Optigen ${ }^{\circledR}$ II mais milho maduro finamente moído, resultou na produção similar de leite e no aumento da síntese relativa de proteína microbiana no rúmen, sem induzir aumento no teor de NUL, observado quando o farelo de soja foi substituído por Optigen ${ }^{\circledR}$ II mais silagem de milho. Essa estratégia de substituição parcial do farelo de soja por Optigen ${ }^{\circledR}$ II mais milho moído também se mostrou promissora pela possibilidade de melhorar a eficiência leiteira, dada pela relação entre o leite produzido e o consumo de alimentos.

Nos dois ensaios experimentais aqui relatados, bem como nos demais trabalhos revisados, a típica inclusão de ureia de liberação lenta na dieta de vacas lactantes tem ficado ao redor de $150 \mathrm{~g}$ diárias, o que permite a retirada de $1,0 \mathrm{~kg}$ de farelo de soja, e assim caracteriza-se a substituição parcial. Ao assumir uma suplementação de $150 \mathrm{~g} / \mathrm{vaca} / \mathrm{d}$ e a cotação do Optigen ${ }^{\circledR} \mathrm{II}$ a $\mathrm{R} \$ 3,65 / \mathrm{kg}$ (janeiro de 2012), pode-se estimar em $\mathrm{R} \$ 0,55 / \mathrm{vaca} / \mathrm{d}$ o custo dessa suplementação. Deve-se enfatizar que o mais relevante é estimar o novo custo alimentar da dieta com a substituição parcial do farelo de soja. Assim, na medida em que o farelo de soja aumentar sua cotação, mais economicamente interessante será a inclusão dietética da ureia de liberação lenta.

\section{AGRADECIMENTOS}

A fazenda Rhoelandht, de propriedade do Sr. Ronald Rabbers, no município de Castro, PR, e à fazenda Frankanna, de propriedade do Sr. Frank Dijkstra, no município de Carambei, PR, por permitir a realização deste trabalho.

\section{REFERÊNCIAS}

ARRIAGA, H.; PINTO, M.; CALSAMIGLIA, S.; MERINO, P. Nutritional and management strategies on nitrogen and phosphorus use efficiency of lactating dairy cattle on commercial farms: An environmental perspective. Journal of Dairy Science, v.92, n.1, p. 204-215, 2009.

BUTLER, W.R. Effect of protein nutrition on ovarian and uterine physiology in dairy cattle. Journal of Dairy Science, v.81, n.9, p.2533-2539, 1998.

CHEN, X.B.; GOMES, J. Estimation of microbial protein supply to sheep and cattle based on urinary excretion of purine derivatives: an overview of the technical details. Bucksburn: Rowett Research Institute, 1995. 21p. 
Rev. Bras. Saúde Prod. Anim., Salvador, v.13, n.2, p.383-395 abr./jun., 2012 http://www.rbspa.ufba.br ISSN 15199940

GALO, E.; EMANUEL, S.M.;

SNIFFEN, C.J.; WHITE, J.H.; KNAPP, J.R. Effect of a polymer-coat urea product on nitrogen metabolism in lactating dairy cattle. Journal of Dairy Science, v.86, n.6, p.2154-2162, 2003.

HARRISON, G.A.; TRICARICO, J.M.; DAWSON, K.A. Effects of urea and Optigen ${ }^{\circledR}$ II on ruminal fermentation and microbial protein synthesis in rumensimulating cultures. In:

NUTRITIONAL

BIOTECHNOLOGY IN THE FEED AND FOOD INDUSTRIES, 2006, Lexington. Proceedings... Lexington: Alltech, 2006.

INOSTROZA, J.F.; SHAVER, R.D.; CABRERA, V.E.; TRICÁRICO, J.M. Effect of diets containing a controlledrelease urea product on milk yield, milk composition, and milk component yields in commercial Wisconsin dairy herds and economic implications. Professional Animal Scientist, v.28, p.175-180, 2010.

JONKER, J.S.; KOHN, R.A.; HIGH, J. Dairy herd management practices that impact nitrogen utilization efficiency. Journal of Dairy Science, v.85, n.5, p.1218-1226, 2002.

LAPIERRE, H.; LOBLEY, G.E.

Nitrogen recycling in the ruminant: a review. Journal of Dairy Science, v.84, n.1, p.223-236, 2001.

NATIONAL RESEARCH COUNCIL NRC. Nutrient requirements of dairy cattle.7.ed.rev. Washington: National Academy Press, 2001.

RAJALA-SCHULTZ, P.J.; SAVILLE, W.J.A.; FRAZER, G.S.; WITTUM, T.E. Association between milk urea nitrogen and fertility in Ohio dairy cows. Journal of Dairy Science, v.84, n.2, p.482-489, 2001.
REYNOLDS, C.K.; KRISTENSEN, N.B. Nitrogen recycling through the gut and the nitrogen economy of ruminants: an asynchronous symbiosis. Journal of Dairy Science, v.86, p.293-305, 2008. Suppl. E.

SANTOS, J.F.; DIAS JÚNIOR, G.S.; BITENCOURT, L.L.; LOPES, N.M.; SIÉCOLA JÚNIOR, S.; SILVA, J.R.M.; PEREIRA, R.A.N.; PEREIRA, M.N. Resposta de vacas leiteiras à substituição parcial de farelo de soja por ureia encapsulada. Arquivo Brasileiro de Medicina Veterinária e Zootecnia, v.63, n.2, p.423-432, 2011.

\section{SAS INSTITUTE. SAS/STAT User's Guide. 9 ed. Cary, 2004.}

SOUZA, V.L.; ALMEIDA, R.; SILVA, D.F.F.; PIEKARSKI, P.R.B.; JESUS, C.P.; PEREIRA, M.N. Substituição parcial de farelo de soja por uréia protegida na produção e composição do leite. Arquivo Brasileiro de Medicina Veterinária e Zootecnia, v.62, n.6, p.1415-1422, 2010.

\section{VAN SOEST, P.J.; ROBERTSON,} J.B.; LEWIS, B.A. Symposium: carbohydrate methodology, metabolism, and nutritional implications in dairy cattle. Journal of Dairy Science, v.74, n.10, p.35833597, 1991.

WILDMAN, E.E.; JONES, G.M.; WAGNER, P.E.; BOMAN, R.L.; TROUTT JÚNIOR, H.F.; SECH, T.N. A dairy cow body condition scoring system and its relationship to selected production characteristics. Journal of Dairy Science, v.65, n.3, p.495-501, 1982.

Data de recebimento: 11/04/2011

Data de aprovação: 04/03/2012 